\title{
O USO DAS TECNOLOGIAS DE INFORMAÇÃO E COMUNICAÇÃO APLICADAS COMO TECNOLOGIA ASSISTIVA NA CONSTRUÇÃ O DO CONHECIMENTO DOS ALUNOS COM DEFICIÊNCIA VISUAL QUE FREQUENTAM AS SALAS DE RECURSOS MULTIFUNCIONAIS
}

\author{
Raquel Rosan Christino GITAHY ${ }^{1}$ \\ Jessé Pessoa da SILVA ${ }^{2}$ \\ Adriana Aparecida de Lima TERÇARIOL ${ }^{3}$
}

RESUMO: Essa pesquisa objetivou investigar a contribuição trazida pelo uso das tecnologias de informação e comunicação aplicadas como tecnologia assistiva na construção do conhecimento dos alunos com deficiência visual que frequentaram a sala de recursos multifuncionais. Foram sujeitos da pesquisa dois estudantes com deficiência visual de diferentes anos escolares que frequentam a sala de recursos multifuncionais de duas instituições de ensino. Além dos estudantes, também foram sujeitos da pesquisa as professoras das respectivas salas de recursos multifuncionais que estes frequentam e os professores que os atenderam no ensino regular. Para alcançar o objetivo, inicialmente, foi consultado o referencial teórico e, posteriormente foi realizado o procedimento de estudo de campo por meio do instrumento de coleta entrevista. Os resultados constataram que as duas instituições de ensino pesquisadas ainda estão construindo seu fazer pedagógico em relação ao uso e apropriação das tecnologias de informação e comunicação quando utilizadas na sala de recurso multifuncional como tecnologia assistiva, sendo de fundamental importância a formação docente para a apropriação das tecnologias de informação e comunicação principalmente em relação ao trabalho com a tecnologia assistiva nos ambientes educacionais para que este desenvolva competências e habilidades que permitam construir práticas pedagógicas em congruência com estas tecnologias.

PALAVRAS-CHAVE: Educação especial. Deficiente visual. Sala de recursos multifuncionais. Tecnologias da informação e da comunicação. Tecnologia assistiva.

\section{INTRODUÇÃO}

As tecnologias de informação e comunicação tem o objetivo de facilitar a comunicação e o acesso à informação, assim como o desenvolvimento de capacidades e competências funcionais dos estudantes com deficiência visual contribuindo para o seu acesso à educação formal. O trabalho com essas tecnologias vem amenizar as barreiras causadas pela deficiência e inserir esses indivíduos em ambientes ricos para a

${ }^{1}$ Docente. UEMS - Universidade Estadual do Mato Grosso do Sul. Faculdade de Direito. Dourados - MS - Brasil. 79804-970. Docente e pesquisadora. UNOESTE - Universidade do Oeste Paulista. Faculdade de Direito. Programa de Mestrado em Educação. Presidente Prudente - SP - Brasil. 19050-920 gitahy@uems.br.

${ }^{2}$ Docente da disciplina de Geografia. EE Semíramis C.B. da Rocha e Viriato Bandeira. Coxim - MS Brasil.79400-000 - jesse_cxms@ hotmail.com.

${ }^{3}$ Docente no curso de Pedagogia. Uninove. São Paulo- SP- Brasil. 03155-000. UNOESTE - Universidade do Oeste Paulista. Faculdade de Artes, Ciências, Letras e Educação - Programa de Mestrado em Educação. Presidente Prudente - SP - Brasil. 19050-920 - atercariol@gmail.com. 
aprendizagem, proporcionando a superação destas barreiras impostas pelas suas limitações e pelo meio. Conforme Radabaugh (1993, p. 3), “[...] para as pessoas sem deficiência, a tecnologia torna as coisas mais fáceis. Para as pessoas com deficiência, a tecnologia torna as coisas possíveis".

No entanto, apesar dessas tecnologias demonstrarem seu valor como facilitadoras para a aprendizagem, convém salientar que o seu aproveitamento pedagógico continua a carecer de uma reflexão profunda. Assim este estudo teve a intenção de investigar a contribuição trazida pelo uso das tecnologias de informação e comunicação aplicadas como tecnologia assistiva na construção do conhecimento dos alunos com deficiência visual que frequentaram a salas de recursos multifuncionais.

\section{CONTEXTO}

A Organização Mundial da Saúde (2008) considera que a deficiência visual é uma deficiência sensorial onde o sistema visual de coleta de informações pode ser parcialmente ou totalmente prejudicado. Desta maneira, quando se fala de deficiência visual, estamos falando de uma população bastante heterogênea.

Devido ao dano parcial ou total no sistema visual de coleta de informações, o deficiente visual recorre aos demais sistemas sensoriais, para conhecer o mundo à sua volta. Disso decorrem certas peculiaridades na construção do seu desenvolvimento e da sua aprendizagem.

Apesar de ser mais lento que a visão é através do 'tato' que as informações sobre os objetos mais próximos podem ser coletadas com bastante precisão, é por isto que "a exploração dos objetos grandes é fragmentária e sequencial" (OCHAÍTA; ESPINOSA, 2004, p. 151).

Outro recurso de aprendizagem considerado de grande importância é a 'audição'. Segundo Ochaíta e Espinosa (2004, p.151) a 'audição' é utilizada “[...] com uma função telerreceptora para a localização e identificação de objetos e pessoas no espaço, funções para as quais é menos precisa que a visão”. Já o 'olfato' tem a função de auxiliar os demais sistemas sensoriais na tarefa complexa de reconhecer pessoas e ambientes. E por fim, o sistema proprioceptivo que fornece informações preciosas para a mobilidade e a orientação na ausência da visão.

Para a inclusão do deficiente visual no processo de aprendizagem tanto dos conteúdos curriculares escolares como do mundo em si, os materiais e recursos serão de 
fundamental importância. Os recursos didáticos então serão todos aqueles materiais físicos utilizados com maior ou menor frequência em todas as disciplinas (CERQUEIRA; FERREIRA, 2000).

Um complemento que vem auxiliar o trabalho com o deficiente visual no ensino regular é a sala de recurso multifuncional, criada em 2007 pela portaria normativa $\mathrm{n}^{\circ} 13$ (BRASIL, 2007), ela atende a todos os alunos com visão subnormal e cegos que estejam matriculados no estabelecimento em qualquer série ou grau.

Definida pelos gestores dos sistemas de ensino, a sala de recursos multifuncionais é organizada como sala do Tipo I e Tipo II. Sendo que as salas do Tipo I são planejadas para atender às pessoas com as mais diversas deficiências, à exceção da pessoa com deficiência visual, que é contemplada na Sala Tipo II.

Em se tratando de alunos deficientes visuais ou de baixa visão e sua relação com a sala de recursos multifuncionais, após avaliação educacional e desenvolvimento de atividades introdutórias, os mesmos podem ser encaminhados a uma classe comum correspondente ao seu nível de adiantamento, recorrendo à sala de recursos quando encontrar dificuldades de aprendizagem decorrentes de problemas impostos por sua limitação visual, cuja solução seja impossível por meio dos recursos utilizados pelo professor do ensino regular.

Apesar do processo educativo do aluno ser desenvolvido na classe comum em que está matriculado, o mesmo poderá recorrer à sala de recursos sempre que necessitar de materiais ou equipamentos, suplementação de aulas por intermédio de material didático que facilite a concretização do aprendizado, ou ainda, para o desenvolvimento de atividades específicas como atividades da vida diária, orientação e mobilidade, treinamento da visão residual, datilografia braille e informática, dentre outras atividades. Sendo um espaço organizado com materiais pedagógicos, tecnológico e mobiliário adaptados, é ideal para o atendimento às necessidades educacionais especiais dos alunos. E é aqui que se encontra inserida a tecnologia de informação e comunicação.

As tecnologias de informação e comunicação podem ser definidas como:

[...] uma série de tecnologias que geralmente incluem o computador e que, quando combinadas ou interconectadas, são caracterizadas pelo seu poder de memorizar, processar, tornar acessível (na tela ou em outro suporte) e transmitir, em princípio para qualquer lugar, uma quantidade virtualmente ilimitada e extremamente diversificada de dados (GRÉGOIRE; BRACEWELL; LAFERRIÈRE, 1996, p. 1). 
E é essa tecnologia de informação e comunicação que pode constituir-se uma ferramenta a serviço do processo de ensino-aprendizagem para que as escolas se tornem inclusivas, quando bem utilizadas. Através das tecnologias de informação e comunicação bem orientada é possível fazer o objeto de estudo sair das paredes da sala de aula e da escola, e levar o aluno a aventurar-se no mundo do conhecimento, sendo que nessa aventura tanto professor como aluno serão parceiros e sujeitos do processo de conhecimento, cada um atuando segundo o seu papel e nível de desenvolvimento.

E observar e respeitar o nível de desenvolvimento de cada aluno é um fator de grande importância nos dias atuais, pois a diversidade é uma característica cada vez mais dominante na sociedade atual, e cabe à escola se adaptar no sentido de promover a igualdade de oportunidades educativas para seus alunos, para tanto é preciso que se considere não só as vivências diversificadas como também os ritmos e tipos de aprendizagem diferentes.

E entre os recursos disponíveis podem-se relacionar as tecnologias de informação e comunicação, pois, por meio dessas ferramentas é ofertada aos alunos deficiente visual a possibilidade de acessar o currículo e a construção de novos conhecimentos, desenvolvendo atividades que, anteriormente, lhes eram de difícil acesso ou até mesmo impossível de serem executadas. Diante do exposto, verifica-se que a tecnologia de informação e comunicação facilitará “[...] o acesso ao conhecimento, à aprendizagem, à ocupação dos tempos livres, ao lazer, ao desenvolvimento de capacidades intelectuais, ao contacto com grupos de interesse comuns; evitarão a exclusão e contribuirão para uma integração plena" (SANTOS, 2006, p. 119).

Ao desenvolver novas estratégias, por intermédio das tecnologias de informação e comunicação, as escolas, além de beneficiarem todos os alunos, também estarão beneficiando os alunos com deficiência visual, pois, de modo geral essas tecnologias quando usadas a favor da inclusão de pessoas com necessidades educativas especiais podem:

Criar maiores níveis de autonomia; ser um contributo inestimável nas áreas do desenvolvimento cognitivo, psicomotor, meio alternativo de comunicação e como meio facilitador da realização de inúmeras tarefas; ser a única alternativa que alguns alunos com necessidades educativas especiais têm para interagir com o meio envolvente; ser 
uma forma de ultrapassar barreiras físicas e sócio-emocionais. (COSTA, 2010, p. 58).

No entanto, é preciso ter sempre o cuidado para que a tecnologia de informação e comunicação não seja vista como ferramenta exclusiva ou até mesmo milagrosa, ela como qualquer outra ferramenta educativa deve ser "[...] integrada numa estratégia de intervenção bem definida já que por si próprias não alteram nada e não é a solução" (COSTA, 2010, p. 59) para todas as situações de dificuldades de aprendizagem.

As tecnologias de informação e comunicação são extremamente úteis quando utilizadas com as denominadas tecnologias assistiva, que são "[...] todo o arsenal de recursos e serviços que contribuem para proporcionar ou ampliar habilidades funcionais de pessoas com deficiência e consequentemente promover vida independente e inclusão" (BERSCH; TORNOLLI, 2006 apud BERSCH, 2013, p. 2).

Pode-se observar que a tecnologia assistiva é uma infinidade de recursos oferecidos para a pessoa com deficiência com o objetivo de favorecer e simplificar as atividades do cotidiano e educacional. É importante ressaltar que, a tecnologia assistiva se estende para todos os ambientes da escola e não somente aos recursos oferecidos dentro da sala de aula, possibilitando dessa forma "o acesso de todos, todo tempo" (EMER, 2011, p. 69), um exemplo de tecnologia assistiva que favorece o desempenho autônomo e independente em uma tarefa rotineira são os talheres modificados que oferecem autonomia durante a hora em que a merenda é servida.

Os espaços onde a tecnologia assistiva deverá ser praticada segundo orientação dada pela Nota Técnica - SEESP/GAB/n. 11/2010 (BRASIL, 2010b) são nas salas de recursos multifuncionais, e os serviços e recursos oferecidos pela tecnologia assistiva mais usuais na área educacional e encontrados na escola são:

[...] a) livros adaptados para baixa visão ou em braile; b) computadores com leitores de tela; c) teclado ergonômico, mini teclado ou teclado expandido, teclado colmeia, teclado braile, teclado falado e teclado de conceitos; d) apontadores e ponteiros de cabeça; e) tela sensível ao toque; f) software de reconhecimento de voz; g) mouse adaptado a necessidade do usuário; $h$ ) possibilidades do próprio computador para ofertar acessibilidade ao usuário, como por exemplo, aumentar os caracteres ou redefinir o teclado ou o mouse; e i) programas de digitalizadores de voz (EMER, 2011, p. 72).

Porém, como todo recurso ou serviço pedagógico é preciso que se tenha um planejamento, pois como coloca Bersch (2013, p.11) a tecnologia assistiva "[...] deve 
ser entendida como o 'recurso do usuário' e não como 'recurso do profissional"', neste caso o professor. Vale advertir que não se deve confundir tecnologia assistiva com tecnologia educacional. Tecnologia educacional é quando:

Um aluno com deficiência física nos membros inferiores e que faz uso de cadeira de rodas, utilizará o computador com o mesmo objetivo que seus colegas: pesquisar na web [...]. O computador é para este aluno, como para seus colegas, uma ferramenta tecnológica aplicada no contexto educacional e, neste caso, não se trata de Tecnologia Assistiva (BERSCH, 2013, p 12).

E a tecnologia assistiva é quando a mesma for:

[...] utilizada por um aluno com deficiência e tem por objetivo romper barreiras sensoriais, motoras ou cognitivas que limitam/impedem seu acesso às informações ou limitam/impedem o registro e expressão sobre os conhecimentos adquiridos por ele; quando favorecem seu acesso e participação ativa e autônoma em projetos pedagógicos; quando possibilitam a manipulação de objetos de estudos; quando percebemos que sem este recurso tecnológico a participação ativa do aluno no desafio de aprendizagem seria restrito ou inexistente (BERSCH, 2013, p.12).

A relevância da tecnologia assistiva principalmente quando utilizada pelo aluno com deficiência visual está na objetividade de seu trabalho. Assim, o docente que for fazer uso da mesma deve procurar conhecer as dificuldades do aluno, para escolher qual tecnologia assistiva que melhor se adequará como ferramenta mediadora para que barreiras impostas pela deficiência apresentada possam ser eliminadas.

Como recursos oferecidos dentro da sala de aula as tecnologias assistivas possuem metodologias para serem corretamente trabalhadas e assim obter um resultado final positivo. Dessa forma, é preciso que no planejamento didático predomine a organização aberta e flexível, e contemple experiências e projetos, selecionando o que melhor atende ao aluno tornando-se uma ponte para a abertura de novos horizontes nos processos de aprendizagem e desenvolvimento de alunos com deficiência.

$\mathrm{Na}$ atualidade dentre as estratégias utilizadas para potencializar o processo de ensino-aprendizagem dos alunos com deficiência visual para que os mesmos possam desenvolver suas habilidades e superar seus limites, auxiliando-os na sua inserção no mundo globalizado, as escolas têm recorrido às tecnologias de informação e comunicação, na qual as mesmas vêm se mostrando uma excelente ferramenta. De 
acordo com Soares, Lira, Santos, Oliveira e Costa: [...] o processo de ensinoaprendizagem, auxiliado pelas Tecnologias de Informação e Comunicação, potencializa o ensino de tal forma que amplia as possibilidades de inclusão digital e social nas escolas, principalmente para alunos com necessidades educativas especiais (SOARES et al., 2013).

Observa-se que essa ferramenta vem facilitar a vida desses sujeitos. Um exemplo de algumas tecnologias que ofereceram maior acessibilidade aos deficientes visuais são o "Braille sem papel, Braille digital ou Braille eletrônico que são terminais Braille, periféricos acoplados a um microcomputador, que transformam em texto Braille toda a informação digital [...]" (PORTES, 2013, p.98) e os leitores de tela com síntese de voz que reproduz “[...] fonemas que são gerados sem o auxílio de pré-gravação, transformando informações binárias em sinais audíveis” (JUNIO et al., 2011, p.165).

Onde uso dessas ferramentas tem o objetivo de criar situações favoráveis ao processo ensino-aprendizagem, assim, é preciso que ao serem selecionadas, as mesmas sejam adaptadas aos conhecimentos já adquiridos e a outros, a serem adquiridos.

\section{METODOLOGIA}

A pesquisa foi aprovada pelo comitê de Ética da Plataforma Brasil $n^{\circ}$ 09208/2013. Os critérios para seleção das escolas que foram alvo desta pesquisa foram: ser escolas públicas da Educação Básica, na cidade de Coxim, Mato Grosso do Sul, que tivessem alunos com deficiência visual, frequentando as suas salas de aula pertencentes às duas redes públicas de educação, municipal e estadual.

No primeiro momento foi realizado um levantamento bibliográfico, depois foram realizadas entrevistas com as professoras das salas de recursos multifuncionais, as professoras que trabalham com aluno com deficiência visual no ensino regular, e alunos com deficiência visual/baixa visão. A análise das entrevistas foi organizada em torno de três polos cronológicos: pré-análise; exploração do material; e, o tratamento, a inferência e a interpretação dos resultados obtidos (BARDIN, 1970).

$\mathrm{Na}$ fase de pré-análise, foi feita apenas a leitura flutuante das entrevistas realizadas, com o objetivo de conhecer de cada indivíduo e permitir a emergência de impressões e orientações. A exploração do material nada mais foi do que codificar e enumerar o material, em função de regras previamente formuladas, sendo que para realizá-la utilizaram-se as seguintes técnicas: análise de avaliação, categorial, da 
enunciação, da expressão, das relações e do discurso. (BARDIN, 1970). A fim de satisfazer os objetivos dessa pesquisa, foi utilizada a técnica de análise categorial nas entrevistas realizadas que "[...] funciona por operações de desmembramento do texto em unidades, em categorias segundo reagrupamentos analógicos" (BARDIN, 1970, p. 153). Em outras palavras, ao se realizar a leitura flutuante, é possível observar termos e palavras que se remetem a uma categoria já identificada no referencial teórico e que ajudará o pesquisador a encontrar respostas para a questão e os objetivos de pesquisa. Por meio desses instrumentos de coleta de dados foi possível a compreensão do processo de trabalho como um todo e suas possíveis lacunas, ou seja, o papel de cada um dos atores - sujeitos no processo, do objeto e dos meios utilizados, necessários à conclusão da investigação.

\section{RESULTADOS E DISCUSSÃO}

\section{Professores das salas de recursos multifuncionais}

As duas docentes possuem formação necessária para atuarem nas salas de recursos multifuncionais, em relação à formação para o uso das tecnologias de informação e comunicação e tecnologia assistiva oferecidas pelas salas de recursos multifuncionais, verificou-se que apenas uma das docentes possui formação específica para atuar com a tecnologia de informação e comunicação e tecnologia assistiva, conforme relato abaixo:

Sim. Tenho formação acadêmica em Educação Inclusiva e cursos de capacitação e formação continuada para atuar em Sala de Recursos Multifuncional (Professora A).

Apenas cursos básicos e gerais, nos dois casos (Professora B)

Sabe-se que a formação é fator importante, se não o mais importante para a qualidade da educação, pois uma "educação de qualidade [...] aparece como componente crucial dos processos emancipatórios" (DEMO, 1992, p. 28). Educação de qualidade e formação docente se complementam, uma não acontece sem a outra. É inegável a necessidade da formação docente para que haja uma melhoria efetiva na educação brasileira, em todos os seus níveis. Se a formação básica do professor é uma condição clássica de instrumentação crucial da cidadania, e vem encabeçando a relação 
dos problemas a ser enfrentada por todo o sistema educacional brasileiro, a formação de professores especializados em educação especial, segundo Mendes Junior e Tosta (2012), enfrenta sérios desafios também, desafios estes decorrentes tanto do contexto problemático das reformas propostas para a formação de professores em geral (reformas apoiadas pelos organismos internacionais), quanto da própria história dessa área específica de formação.

Vygotsky (1997) assevera que o professor, enquanto núcleo do processo educativo do aluno precisa buscar meios para que o mesmo com deficiência, tal como os demais, tenha condições de adquirir conhecimento.

Assim, o professor precisa ter a compreensão não somente da deficiência apresentada pelo seu aluno, mas também do seu desenvolvimento, dos seus estilos de aprendizagem, suas motivações, seus interesses e de sua história socioambiental-escolar, de identificar quais recursos são adequados para que a aprendizagem aconteça de forma eficiente e eficaz, sendo que tal compreensão acontecerá por meio de uma formação adequada.

Um dos meios utilizados pelo Estado para suprir essa deficiência de formação específica na área e a necessidade intrínseca de atualização é a capacitação continuada, sobre a sua oferta aos professores que atuam em sala de recursos multifuncionais para o trabalho com as tecnologias de informação e comunicação e tecnologia assistiva e sua periodicidade, de acordo com informação da professora 'A' o Estado oferece capacitação tanto na área da educação especial bem como para as salas de recursos multifuncionais sendo que o município oferece apenas segundo a professora 'B' "algumas reuniões mensais para estudo" sobre os tipos de deficiências.

Sabe-se que a conexão entre a formação inicial e a permanente é imprescindível e essa conexão acontece diante da oferta de políticas públicas que venham estimular tal formação, no entanto, apesar dos avanços das políticas públicas de educação inclusiva, decorrente da instituição de políticas públicas estruturantes, objetivando assegurar e amparar o direito das pessoas com deficiência à educação, é preciso ter em mente, contudo, que a existência de uma lei não garante infelizmente que os direitos estejam sendo assegurados na prática do dia-a-dia.

Certamente a formação docente é uma área que merece atenção no contexto da inclusão, a lacuna deixada muitas vezes pela formação inicial e pela própria característica dinâmica da educação levam alguns professores a buscarem $\mathrm{o}$ aperfeiçoamento como caminho para desenvolver a sua prática de forma a atender 
adequadamente os alunos (GONZÁLEZ, 2002). Formar professores especializados em educação especial não é algo comum na realidade brasileira, assim é de suma importância que se prepararem os professores para o atendimento aos alunos que necessitem um atendimento especializado, assim a capacitação visa direcionar o profissional a um processo de educação e reciclagem (GONZÁLEZ, 2002).

Considerando que a sala de recursos multifuncionais é um serviço de apoio especializado, de natureza pedagógica que vem complementar ou suplementar o atendimento educacional realizado em classe comum é preciso que o profissional que atue nesta sala tenha conhecimentos específicos para buscar estratégias e utilizar as ferramentas disponíveis dessas salas a fim que a mesmas possam desenvolver o máximo das possibilidades dos alunos que a frequentam (GONZÁLEZ, 2002). E se tratando das tecnologias de informações e comunicação e as tecnologias assistiva a capacitação é importante, pois a mesma vem mostrar como a informática pode ser uma ferramenta pedagógica. Reforçando essa ideia, Nogueira, Oliveira, Souza Júnior e Oliveira (2013, p. 2) considera que: “[...] a utilização das Tecnologias da Informação e Comunicação no contexto escolar efetivamente como ferramenta de ensino facilitadora da aprendizagem dos alunos, está fortemente influenciada pela formação docente, seja ela inicial ou continuada".

Diante da exposição acima, verifica-se a importância da capacitação dos professores quanto ao uso das tecnologias para que as mesmas possam de fato ser inseridas com responsabilidade na educação.

Quanto ao tipo de sala de recursos multifuncionais que as escolas possuem de acordo com a docente da escola Municipal Estudante William Tavares de Oliveira a escola "possui modelo convencional - padrão", não dando maiores informações sobre o tipo de sala e os recursos oferecidos. Na Escola Estadual Padre Nunes, segundo informação da docente, a sala de recursos multifuncionais é do tipo II e possui: micro computadores, monitores, fone de ouvido e microfones, scanners, impressora laser, teclado e colmeia, mouse e acionador de pressão, laptop, materiais e jogos pedagógicos e acessíveis, softwares para comunicação alternativa, note books com acessibilidades e com leitor de tela como o DOSVOX e o falador, lupas manuais e lupa eletrônica, plano inclinado, mesas, cadeiras, armário e quadro branco.

Fazendo uma comparação entre o que preconiza o programa de implantação de sala de recursos multifuncionais em relação à tecnologia de informação e a tecnologia assistiva e o que a escola oferece observa-se que a mesma possui os equipamentos e 
materiais necessários preconizados pelo programa de salas de recursos multifuncionais em relação à tecnologia de informação e comunicação e tecnologia assistiva.

Em relação ao tipo de tecnologia de informação e comunicação utilizada como tecnologia assistiva para o trabalho com alunos com deficiência visual segundo as docentes na sala de recursos multifuncionais os recursos utilizados para o trabalho com o aluno com deficiência visual, são: ampliador de tela, aumento do tamanho do cursor para maior visibilidade, jogos pedagógicos, Power Point, correio eletrônico e-mail e Blogs. A resposta das docentes, porém, não deixou claro como e qual a frequência com que as mesmas utilizam essa tecnologia de informação e comunicação como tecnologia assistiva, como se pode verificar nas colocações a seguir:

\begin{abstract}
Na SRM, da Escola em que atuo, existem vários recursos [...], porém com o estudante com deficiência visual, utiliza-se tais recursos, computadores, algumas ferramentas de acessibilidade, ampliador de tela, uso letra bastão, aumento o tamanho do cursor, para maior visibilidade, plano inclinado para leitura, jogos pedagógicos. Recursos com imagens textos ampliados. Power Point, correio eletrônico e-mail e Blogs (professor A)

Atendimentos com aplicativos de computador. (professor B)
\end{abstract}

Finalizando esse tópico é importante salientar que a escolha de como a tecnologia de informação e comunicação a ser adotado pelo docente da sala de recursos multifuncionais como tecnologia assistiva está ligada diretamente aos objetivos que o educador deseja alcançar no seu trabalho com seu aluno.

\title{
2 Regentes das salas de ensino regular
}

Ambos docentes possuem formação em Pedagogia, porém quanto à formação para o uso de tecnologia de informação e comunicação e tecnologia assistiva, os dois docentes informaram que possuem apenas para trabalhar com a tecnologia de informação e comunicação, como visto a seguir: Não (Professor C). Não. Tenho apenas conhecimento baseado em leituras de livros sobre tecnologia assistida, porém, quanto à participação de cursos nesta área, ainda não houve a possibilidade de participar (Professor D).

Observa-se que à tecnologia assistiva é uma área de conhecimento que os mesmos não possuem nenhuma formação, sendo que o seu conhecimento é de importância considerável para desenvolver o trabalho com os seus alunos com 
deficiência visual, trabalhos estes que devem estar centrados “[...] na busca de estratégias de ajuda [...], a fim de que estes possam desenvolver ao máximo suas possibilidades" (GONZÁLEZ, 2002, p. 241).

Em relação às políticas públicas para capacitação dos professores de sala de ensino regular que possuem alunos com necessidades educativas especiais os dois docentes responderam que é oferecido, no entanto no que se refere à periodicidade, o docente da escola municipal acrescenta que "são em número insuficiente".

Políticas de capacitação dos professores que atuam em sala de ensino regular para trabalhar com a inclusão é uma necessidade intrínseca e deve fazer parte permanente do desenvolvimento profissional docente (BRASIL, 2002), pois somente assim o professor poderá desenvolver uma intervenção educativa que atue adequadamente àqueles alunos que de alguma forma necessitam de uma atenção diferenciada para que sua aprendizagem aconteça. Apesar da capacitação docente estar prevista na LDB em seu art. 59 § III (BRASIL, 2010c), o que se observa é que a prática da mesma está longe do ideal necessário para se desenvolver uma educação inclusiva de qualidade.

Assim para suprir essa deficiência de conhecimento o Estado oferece como apoio a esses professores de sala de ensino regular as salas de recursos multifuncionais, quando questionados quais as melhorias apresentadas pelos alunos com deficiência visual que frequentam a sala de recursos multifuncionais, os dois professores apontaram melhorias como: auxilio significativo na aprendizagem cognitiva, melhor socialização, interesse e participação nas atividades desenvolvidas em sala de aula. Para os professores essa melhoria apresentada pelos estudantes é decorrente do ensino especializado oferecido na sala de recursos multifuncionais cujo objetivo é desenvolver no aluno que a frequenta habilidades necessárias para superar as dificuldades que a deficiência lhe impõe, por meio da utilização de recursos, no caso dos alunos deficientes visuais, das tecnologias de comunicação e informação como a comunicação alternativa e os recursos de acessibilidade ao computador, da tecnologia assistiva, entre outros (BRASIL, 2010a).

Sobre a relação entre a sala de aula regular, a sala de recursos multifuncionais, as tecnologias de informação e comunicação e as tecnologias assistiva os dois professores afirmaram que essa relação é muito importante, porém na realidade ela ainda está distante. Conforme colocação abaixo: 
A relação destes aspectos é de suma importância, pois, ambos são recursos e ferramentas que certamente iria auxiliar qualquer estudante portador de necessidades especiais, mas, na realidade não é isso que o sistema oferece, pois, percebe-se que ainda falta muito em relação a aprendizagem destes estudantes portadores de necessidades especiais (Professor C)

Quanto às tecnologias de informação e comunicação há uma interação correlacionada para com as necessidades, bem como na sala de aula regular. Já quanto a sala de recursos multifuncionais $e$ as tecnologias assistivas os parâmetros se 'distanciam', ou seja, não há uma interação precisa, principalmente, para com a interação com os professores da sala regular. Já com o educando o processo é sistemático e contínuo (Professor D).

Dessa acepção pode-se ressaltar que o comprometimento dessa relação pode estar relacionado à falta de conhecimentos, de recursos tecnológicos, do desrespeito à legislação vigente e da forma como a sociedade está organizada de forma a ignorar as diferentes demandas de sua população escolar (GALVÃO FILHO, 2009).

Comparando os dados coletados entre os diferentes instrumentos propostos pode-se observar a urgência, tanto das redes de ensino municipal quanto estadual de ampliar em termos quantitativo e qualitativo o número de formações continuadas referentes ao processo de inclusão escolar, pois os professores que atendem alunos com necessidades educativas especiais, demonstram pouco conhecimento sobre $o$ atendimento educacional especializado, seus recursos e possibilidades. Por meio da capacitação, o professor conhecerá as possibilidades e viabilidades, derrubando as barreiras do medo do desconhecido e atribuindo sentido e significado à prática pedagógica inclusiva, podendo então nessa prática encontrar a legitimação da verdadeira inclusão escolar.

\section{Alunos que frequentam a sala de recursos multifuncionais}

O aluno E possui 11 anos, está no $4^{\circ}$ ano do Ensino Fundamental, e apresenta baixa visão, frequenta a sala de recursos multifuncionais a quase 3 (três) anos e gosta de frequenta-la pois ajuda "a compreender melhor as coisas (conteúdos) que a professora passa em sala". Quanto ao aluno F tem 14 anos, está no $5^{\circ}$ ano do Ensino Fundamental, e apresenta baixa visão e deficiência mental frequenta a Sala de Recursos Multifuncionais a 3 (três) anos e gosta de frequentá-la, pois segundo ele o "atendimento é por aluno (individualizado) e a professora tem paciência ao ensinar as atividades". 
Ainda de acordo com sua colocação "antes eu não conseguia nem passar de ano, essa sala (SRM) é uma beleza!'.

Analisando as respostas acima, a tecnologia de informação e comunicação utilizada como tecnologia assistiva favorece a construção do conhecimento deste aluno. A tecnologia de informação e comunicação, quando utilizada de forma construtiva, contribui para que o indivíduo supere suas deficiências, dando condições nesse caso, para que o aluno possa desenvolver suas potencialidades, demonstrando que, apesar da deficiência, ele pode ser capaz de executar determinadas atividades com certa autonomia. A essa compensação social a que Vygotsky (1997) se refere, consiste numa reação do sujeito (aluno) diante da deficiência, no sentido de superar as limitações impostas pela mesma com base em instrumentos artificiais, nesse caso, a tecnologia de informação e comunicação (mediação simbólica). A tecnologia de informação e comunicação oferece novas formas de explorar o mundo e isto é importante, pois,

As crianças com deficiência (física, auditiva, visual ou mental) têm dificuldades que limitam sua capacidade de interagir com o mundo. Estas dificuldades podem impedir que estas crianças desenvolvam habilidades que formam a base do seu processo de aprendizagem (VALENTE ,1991, p.1).

Como ferramenta de tecnologia assistiva, a tecnologia de informação e comunicação fortalece por meio do apoio de suportes tecnológicos como programas adequados, e-mail e Blogs, por exemplo, o estudante a construir sua aprendizagem. A tecnologia de informação e comunicação pode tanto oferecer possibilidades lúdicas como também ser instrumento mediador entre o mundo real e o aluno. Neste caso a sala de recursos multifuncionais contará com dois mediadores, as tecnologias de comunicação e informação e o professor.

Porém será a mediação feita pelo professor o “[...] processo essencial para tornar possíveis atividades psicológicas voluntárias, intencionais, controladas pelo próprio indivíduo" (OLIVEIRA, 1997, p. 33). E o resultado deste trabalho evidencia que esse tipo de ferramenta quando empregada com objetivos e metodologias adequadas, contribui para uma aprendizagem significativa, pois considera a singularidade dos alunos, estimulando-os a superar suas limitações interpostas pela deficiência, funcionando como um elemento motivador para a busca de caminhos alternativos na execução de atividades. 


\section{CONCLUSÃO}

$\mathrm{Na}$ atualidade, um dos desafios enfrentados pela escola é a necessidade de se trabalhar com a inclusão dos alunos com deficiência, promovendo igualdade de oportunidades para todos. Outro desafio está na qualidade do ensino ofertado nas escolas para estes alunos.

Neste sentido, a inserção das tecnologias de informação e comunicação constitui-se numa importante ferramenta no que se refere à aprendizagem dos alunos com deficiência visual. Considerando as análises dos dados chegou-se às seguintes conclusões:

As salas de recursos multifuncionais são ainda um ambiente pouco conhecido dos professores regentes, eles desconhecem tanto o seu funcionamento como a aplicação de alguns equipamentos como os teclados adaptados e softwares, e essa falta de conhecimento leva esses professores a optarem, quando no momento da elaboração do seu planejamento, pela não utilização desses recursos diferenciados que são oferecidos por essas salas para se trabalhar com alunos com deficiência visual, optando assim por material xerocopiado ampliado.

Assim, para sanar esse problema, o ideal seria uma parceria entre a professora regente e a professora da sala de recursos multifuncionais na elaboração do planejamento, porém essa parceria não vem ocorrendo, e a justificativa dada é que a mesma vem sendo prejudicada devido à dinâmica da escola. A falta de oportunidade de realizar os planejamentos de forma integrada entre os professores regentes que atendem alunos com deficiência visual e o professor da sala de recursos multifuncionais, é um ponto limitante para o trabalho com esses alunos, pois o planejamento em conjunto é um elemento essencial para o desenvolvimento do mesmo.

A falta de formação específica na área, traz prejuízo em relação ao uso adequado dos recursos e seleção das melhores estratégias de ensino para desenvolver o trabalho de mediação junto aos alunos atendidos, no sentido de desenvolver um processo de ensino e aprendizagem efetivo, utilizando os recursos e equipamentos de tecnologia assistiva adequados, pois por si só, os mesmos não trarão contribuição para esses alunos com deficiência visual.

Assim, para que as tecnologias de informação e comunicação sejam utilizadas eficazmente para a abertura de novo horizonte nos processos de aprendizagem e desenvolvimento dos alunos com necessidades educativas especiais, é preciso que o 
projeto político-pedagógico contemple claramente como a mesma será trabalhada dentro da escola e que os docentes não só redimensionem suas práxis, mais que se sensibilizem para a necessidade da construção de uma sociedade e de uma escola realmente inclusivas.

Somente assim poderão apropriar-se das novas linguagens tecnológicas, sendo que esse redimensionamento das práxis com o objetivo de obter uma melhor resposta à demanda educacional contemporânea seja estimulado, é preciso que os programas de formação continuada sejam mais frequentes para dar respostas às demandas e necessidades do exercício profissional, como também capacitem os professores a trabalharem com as salas de recursos multifuncionais e as tecnologias ali oferecidas.

Com relação aos alunos com deficiência visual, concluiu-se que, quando atendidos na sala de recursos multifuncionais e ao utilizarem as tecnologias de informação e comunicação como tecnologia assistiva, apresentaram melhoras significativas na aprendizagem, no entanto, compete ao educador propor novas metodologias e formas de mediação pedagógica em congruência com essas tecnologias de comunicação e informação, para que o processo de aprendizagem ocorra satisfatoriamente para o aluno e o próprio educador.

Esperamos que os profissionais da educação percebam cada vez mais a importância da utilização de recursos inovadores como as tecnologias de informação e comunicação, como a tecnologia assistiva para o desenvolvimento do seu fazer pedagógico, e que este fazer pedagógico seja redimensionando para atender as reais necessidades dos seus alunos, adequando às atividades escolares de acordo com as suas características particulares.

Porém é importante destacar que a inovação, no contexto educacional, não está apenas atrelada ao uso de recursos tecnológicos, mas também à forma de trabalhar. Por isso são necessários estudos que acenem para a busca de novos paradigmas pautados em concepções metodológicas que permitam o uso crítico e criativo das tecnologias de comunicação e informação, trazendo em seu bojo novas perspectivas paras pesquisas futuras.

THE USE OF INFORMATION TECHNOLOGIES AND COMMUNICATION 
ABSTRACT: This research aimed to investigate the contribution brought by the use of information and communication technologies applied to assistive technology in the construction of knowledge of students with visual impairment who attended the multifunction capabilities room. Research subjects were two students with visual impairment in different school years attending the multifunctional room features two educational institutions. In addition to students, the research subjects were also the teachers of the respective multi-functional resources they attend and the teachers who attended the in mainstream education. To achieve the goal, initially, the theoretical framework and was later carried out the field study procedure through the interview collection was consulted. The results found that two educational institutions surveyed are still building their pedagogical regarding the use and appropriation of ICT when used in multifunctional resource room as assistive technology. It is of fundamental importance to teacher training for the appropriation of ICT especially in relation to work with assistive technology in educational environments. Therefore, that it develops skills and abilities that allow building pedagogical practices in congruence with these technologies.

KEYWORDS: Special education. Visually impaired. Multifunction resource room. Information and communication technologies. Assistive technology.

\section{REFERÊNCIAS}

BARDIN, L. Análise de conteúdo. Lisboa: Edições 70, 1970.

BERSCH, R. Introdução à Tecnologia Assistiva. Porto Alegre: [s.n.], 2013.

Disponível em: <http://www.assistiva.com.br/Introducao_Tecnologia_Assistiva.pdf >. Acesso em: 1 abr. 2016.

BRASIL. Ministério da Educação. Secretaria de Educação Especial. Manual de Orientação: Programa de Implantação de Sala de Recursos Multifuncionais. Brasília: MEC, 2010a. Disponível em:

$<$ http://portal.mec.gov.br/index.php?option=com_docman\&view=download\&alias=993 6-manual-orientacao-programa-implantacao-salas-recursos-

multifuncionais\&category_slug=fevereiro-2012-pdf\&Itemid=30192>. Acesso em: 1 abr. 2016.

. Ministério da Educação. Secretaria de Educação Especial. Nota Técnica -

SEESP/GAB $/ \mathbf{n}^{\mathbf{0}}$. 11/2010. Orientações para a institucionalização da Oferta do

Atendimento Educacional Especializado - AEE em Salas de Recursos Multifuncionais, implantadas nas escolas regulares. Brasília: MEC, 2010b. Disponível em:

$<$ http://portal.mec.gov.br/index.php?option $=$ com_docman\&view $=$ download\&alias $=529$ 4-notatecnica-n112010\&category_slug=maio-2010-pdf\&Itemid=30192>. Acesso em: 1 abr. 2016.

. Ministério da Educação. LDB - Lei das Diretrizes e Base da Educação

Nacional. Brasília: MEC, 2010c. 
Portaria Normativa ${ }^{\circ} 13$, de 24 de abril de 2007. Dispõe sobre a criação do Programa de Implantação de Salas de Recursos Multifuncionais. Diário Oficial [da] República Federativa do Brasil. Brasília, DF, n. 80, 26 abr. 2007. Seção1, p. 4. Disponível em: <http://portal.mec.gov.br/arquivos/pdf/multifuncional.pdf >. Acesso em: 1 abr. 2016.

Referencias para formação de professores. Brasília: Ministério da Educação e Cultura, 2002.

CERQUEIRA, J.; FERREIRA, E. M. B. Recursos didáticos na educação especial. Revista Benjamin Constant, Rio de Janeiro, v.6, n.15, p.24-28, 2000. Disponível em: <http://200.156.28.7/Nucleus/media/common/Nossos_Meios_RBC_RevAbr2000_ARTI GO3.RTF>. Acesso em: 1 abr. 2016.

COSTA, M. M. C. M. Criação de recursos digitais para crianças com Necessidades Educativas Especiais do Agrupamento de Escolas de Mindelo. 2010. 97f. Trabalho realizado para a disciplina de Seminário de Projecto, Escola Superior de Educação de Paula Frassinetti, Porto, 2010. Disponível em: <http://repositorio.esepf.pt/bitstream/10000/404/2/PG-TIC-2010_MonicaCosta.pdf>. Acesso em: 1 abr. 2016.

DEMO, P. Formação de professores básicos. Em Aberto, Brasília, v.12, n.54, abr./jun. 1992. Disponível em:

<http://emaberto.inep.gov.br/index.php/emaberto/article/view/1843/1814>. Acesso em: 1 abr. 2016.

EMER, S. O. Inclusão escolar: formação docente para o uso das TIC aplicada como Tecnologia Assistiva na Sala de Recurso Multifuncional e sala de aula. 2011. 164f. Dissertação (Mestrado em Educação) - Faculdade de Educação, Universidade Federal do Rio Grande Sul, Porto Alegre, 2011. Disponível em: <http://www.lume.ufrgs.br/bitstream/handle/10183/36313/0008174 44.pdf?sequence=1>. Acesso em: 1 abr. 2016.

GALVÃO FILHO, T. A. Tecnologia assistiva: de que se trata? In: MACHADO, G. M.; SOBRAL, N. (Org.). Conexões: educação, comunicação, inclusão e interculturalidade. Porto Alegre: Rede Editora, 2009. p.207-235.

GONZÁLEZ, J. A. T. Educação e diversidade: bases didáticas e organizativas. Porto Alegre: Artmed, 2002.

GRÉGOIRE, R.; BRACEWELL, R.; LAFERRIÈRE, T. The contribution of new technologies to learning and teaching in elementary and secondary schools: documentary review. 1996. Disponível em: <http://www.tact.fse.ulaval.ca/fr/html/apport/impact96.html>. Acesso em: 1 abr. 2016.

JUNIO, J. A. et al. Inclusão digital e tecnologia assistiva: avaliação da usabilidade e acessibilidade para deficientes visuais em redes sociais online e celulares. RETEC, Ourinhos, v.4, n.1, p.163-179, 2011. Disponível em: 
$\langle$ http://retec.fatecourinhos.edu.br/index.php/retec/article/view/141>. Acesso em: 1 abr. 2016.

MENDES JÚNIOR, E.; TOSTA, E.I. L. 50 anos de Políticas de Educação Especial no Brasil: movimentos, avanços e retrocessos. 2012. Disponível em: $<$ http://www.ucs.br/etc/conferencias/index.php/ anpedsul/9anpedsul/paper/viewFile/1464/670>. Acesso em: 5 abr. 2016.

NOGUEIRA, L. K. C. et al. Formação de professores e tecnologias da Informação e comunicação - TIC's: uma relação necessária para o uso de recursos tecnológicos na educação. In: CONGRESSO BRASILEIRO DE ENSINO SUPERIOR A DISTÂNCIA, 10., Belém, PA. Anais... Belém, PA: UNIREDE, 2013. Disponível em: <http://www.aedi.ufpa.br/esud/trabalhos/poster/AT2/114324.pdf>. Acesso em: 1 abr. 2016.

OCHAÍTA, E.; ESPINOZA, M. A. Desenvolvimento e intervenção educativa nas crianças cegas ou deficientes visuais. In: COLL, C.; MARCHESI, A.; PALACIOS, J. (Org.). Desenvolvimento psicológico e educação. Porto Alegre: Artmed, 2004. p.151170.

OLIVEIRA, M. K. Vygotsky: Aprendizado e desenvolvimento um processo sóciohistórico. São Paulo: Scipione, 1997.

ORGANIZAÇÃO MUNDIAL DA SAÚDE [OMS]. CID10 - Classificação Estatística Internacional de Doenças e Problemas Relacionados à Saúde: Transtornos visuais e cegueira (H53-H54). São Paulo: Edusp, 2008.

PORTES, R. M. L. Desafios e perspectivas na utilização das TICS no contexto educativo de crianças com deficiência visual. 2013. 187f. Dissertação (Mestrado em Educação) - Faculdade de Educação, Universidade Federal de Uberlândia, Uberlândia, 2013. Disponível em:

<http://repositorio.ufu.br/bitstream/123456789/3530/1/DesafiosPerspectivasUtilizacao.p df>. Acesso em: 1 abr. 2016.

\section{RADABAUGH, M. P. Study on the Financing of Assistive Technology Devices of} Services for Individuals with Disabilities: a report to the president and the congress of the United State, National Council on Disability. 1993. Disponível em:

<http://files.eric.ed.gov/fulltext/ED355696.pdf>. Acesso em: 1 abr. 2016.

SANTOS, J. L. A escrita e as TIC em crianças com Dificuldades de Aprendizagem: um ponto de encontro. 2006. Dissertação (Mestrado em Educação Especial) - Programa de Pós Graduação em Dificuldades de Aprendizagem de Instituto de Estudos da Criança, Universidade do Minho, Braga, Portugal, 2006. Disponível em:

$<$ http://repositorium.sdum.uminho.pt/bitstream/1822/6325/2/A\%20Escrita\%20e\%20as $\% 20$ TIC $\% 20 \mathrm{em} \% 20 \mathrm{Crian} \% \mathrm{C} 3 \%$ A7as\%20com\%20Dificuldades\%20de\%20Aprendiza. pdf>. Acesso em: 2 abr. 2016.

SOARES, A. L. et al. Investigando a tecnologia assistiva para deficientes visuais através de uma experiência de estágio supervisionado. In: SEMINÁRIO NACIONAL DE INCLUSÃO DIGITAL, 2., 2013, Passo Fundo. Anais... Passo Fundo: SENID, 
2013. Disponível em:

<http://gepid.upf.br/senid/download/senid2013/Artigo_Completo/111041.pdf>. Acesso em: 2 abr. 2016.

VALENTE, J. A. (Org.). Liberando a mente: computadores na educação especial.

Campinas, 1991. Disponível em: <http://www.nied.unicamp.br/?q=content/downloadvalente-1991>. Acesso em: 2 abr. 2016.

VYGOTSKY, L. S. Obras escogidas V: fundamentos de defectologia. Tomo 5. Madrid: Visor, 1997. 